\title{
Adaptability of High-Yielding Rice Cultivars in Relation to Biomass Productivity under Moderately Water Stressed Upland Conditions
}

\author{
Tomohiro Hyoda, Koki Homma, Tatsuhiko Shiraiwa, Keisuke Katsura, \\ Takeshi Horie \\ Graduate School of Agriculture, Kyoto University, Kyoto, Japan \\ Email: homma@kais.kyoto-u.ac.jp
}

Received 27 February 2015; accepted 16 March 2015; published 20 March 2015

Copyright (C) 2015 by authors and Scientific Research Publishing Inc.

This work is licensed under the Creative Commons Attribution International License (CC BY). http://creativecommons.org/licenses/by/4.0/

(c) (i) Open Access

\section{Abstract}

Recent studies have focused on the improvement of rice productivity under aerobic conditions for times when water resources and food production are limited. This study aimed to evaluate the adaptability of high-yielding rice cultivars to moderately water-stressed upland conditions in order to contribute breeding. A three-year field experiment in the temperate climate of Kyoto, Japan, indicated that the decrease in yield was mainly derived from a decrease in above-ground total dry matter (TDM) rather than a decrease in harvest index (HI). Although the decrease in TDM was mostly caused by a decrease in radiation use efficiency (RUE), we determined that the key to adapting high-yielding cultivars to upland conditions is intercepted radiation per day (IRPD), governed by leaf area index (LAI). Although the effect was not robust, LAI growth under upland conditions was associated with root length density. RUE was dependent on leaf water potential (LWP), indicating that a plant's ability to maintain LWP under water-stressed conditions is important. The results also suggest the necessity of a canopy analyzer to evaluate LAI, as well as an infrared radiation thermometer to evaluate RUE. Performing such measurements during breeding efforts allows us to select for genotypes that are suitable for less stressed aerobic conditions.

\section{Keywords}

Intercepted Radiation, Radiation Use Efficiency, Root Length Density, Leaf Water Potential, Temperature Difference between Canopy and Air 


\section{Introduction}

Rice is a staple food for about $50 \%$ of people in the world, most of whom live in Asia. The production of rice increased double from 1960 to 2010 depending on yield increase, which was caused by improvement of cultivar, cropping and resource management [1]. However, recent climatic disasters make the production unstable [2]. Together with the aspects of world population increase, we are recommended to improve rice productivity.

Irrigated paddy fields occupy one half of the area devoted to rice cultivation, representing two-thirds of the world's rice production. Recent research indicates that the water available for irrigation has been reduced by limited water resources, as well as increased industrial and city water use [3]. Previous studies indicated the greatest potential for increasing rice production in the face of certain population expansion will involve rainfed and upland rice ecosystems [4] [5]. While the level of rice yield in irrigated conditions has plateaued, yields in rainfed and upland conditions demonstrate room for growth. Thus high-yield production under limited water conditions will be the key to increasing future rice productivity.

Traditionally, rice cultivars have been classified as irrigated, rainfed or upland. In this classification, upland rice generally has low productivity but high tolerance to drought. However, some lowland rice cultivars perform well, even in upland conditions [6]. Cultivars that display the yield potential-enhancing traits of high-yielding lowland cultivars, including adaptation to aerobic soils, have been developed as upland rice [7]. When treated with chemical fertilizer, these cultivars exhibit relatively high yield, not only under upland conditions, but also under flooded lowland conditions. These examples illustrate that cultivars that displayed higher yield under upland conditions also exhibited relatively high yield under irrigated paddy conditions, indicating the possible significance of adapting high-yielding lowland cultivars to water-limited conditions. Some previous studies reported the importance of root features, such as root length and water extraction ability, for adaptability [8]-[11]. However, cultivars with better root performance sometimes displayed reduced yield potential [12] [13]. Further investigation is required to identify the factors that determine adaptability.

The difference in yield between traditional upland cultivars and high-yielding cultivars under upland conditions is mainly derived from harvest index (HI). However, HI improvement in lowland cultivars plateaued until 1980, so breeding strategy enhanced above-ground dry matter productivity [14]. The strategy will be similar for upland rice improvement. Peng et al. [15] reported that a decrease in yield under aerobic conditions as compared to flooded conditions was caused by a decrease in TDM rather than in HI. These facts suggest the importance of dry matter productivity in breeding strategy for upland cultivars.

This study conducted cultivar experiments under flooded and upland conditions in paddy fields to explore factors associated with the adaptability of high-yielding cultivars to limited water conditions. In particular, we focused on dry matter productivity. We tested several high-yielding cultivars, as well as standard and traditional cultivars as references. We measured several features, including radiation use efficiency (RUE), leaf water potential (LWP) and root length density (RLD). On the basis of these results, we discussed which features determined productivity under water-limited conditions, and we suggest certain indexes for use in cultivar selection.

\section{Materials and Methods}

\subsection{Cultivation Methods}

The experiment was conducted at the experimental farm at Kyoto University for 3 years, from 2005-2007. For the experiment, we prepared two adjacent paddy fields, which had been used as flooded paddies by the same management for several years [16]. One field was used for the flooded condition, and the other was used for the upland condition. In 2005 and 2006, 9 cultivars were planted: Takanari, Nipponbare and Yumenohatamochi (Japan), IR72 and IR55423-01 (Apo) (IRRI), B6144-MR-6-0-0 (B6144) and Banten (Indonesia), Mak hin sung (Lao PDR) and WAB 450-IBP-121-4-1 (WAB) (WARDA). In 2007, we planted the same cultivars, except for Yumenohatamochi, Banten and WAB. Takanari and IR72 are high-yielding cultivars for lowland conditions. Apo and B6144 are bred as high-yielding cultivars for upland conditions [7]. WAB is one of the inter-specific lines derived from a cross between O. glaberrima and O. sativa, bred for upland conditions [17]. This line exhibited a paddy yield of more than $700 \mathrm{~g} \cdot \mathrm{m}^{-2}$ under upland conditions in Japan [18]. Nipponbare and Yumenohatamochi are Japanese standard cultivars for lowland and upland conditions, respectively. Banten and Mak hin sung are traditional upland cultivars [19] [20]. These cultivars were tested with three replicates in a randomized block design, for each irrigated and upland condition. The area of each replicate ranged from $4.32 \mathrm{~m}^{2}$ to $9.94 \mathrm{~m}^{2}$. 
In the flooded condition, 3-week-old seedlings were transplanted in late May for a period of 3 years. In the upland condition, the same seedlings were transplanted in 2005 and 2007, while the cultivars were direct seeded in late April of 2006. Each seedling was nursed in a paper pod, with one seed in each cell. We transplanted one plant at each hill. For direct seeding, five seeds were planted for each hill and thinned to one plant one month after seeding. The hill covered an area that was $0.3 \mathrm{~m} \times 0.15 \mathrm{~m}\left(22.2 \mathrm{hill} \cdot \mathrm{m}^{-2}\right)$. We performed basal fertilizer applications $\left(\mathrm{N}-\mathrm{P}_{2} \mathrm{O}_{5}-\mathrm{K}_{2} \mathrm{O}=5 \mathrm{~g} \cdot \mathrm{m}^{-2}-5 \mathrm{~g} \cdot \mathrm{m}^{-2}-5 \mathrm{~g} \cdot \mathrm{m}^{-2}\right.$ ).

Irrigation was applied to the upland condition before plant leaves displayed severe rolling due to water stress. The irrigation dates were 27 June and 1 August in 2005, 10 August and 28 September in 2006, and 12 August in 2007 (Figure 1). During the off season, from November to April, ort was planted as green manure without chemical fertilizer.

\subsection{Measurements}

Rice plants were sampled at heading and maturity for 3 years. For each replicate, we sampled 4 hills in 2005, 2 hills in 2006, and 2 hills in 2007. We selected the hills that had an average number of tillers at each replicate (average of 20 hills). The samples were analyzed to determine the leaf area index (LAI) and dry weight of each organ. At each replicate, paddy yield in dry weight at maturity was measured for 24 hills in 2005 and for 10 hills in 2006 and 2007.

Root length density was measured for flooded and upland conditions in 2005 and only for upland conditions in 2006 and 2007. One plant for each cultivar was sampled in 2005 and one plant for each replicate was sampled in 2006 and 2007. A soil block was taken with each root, still attached to the plant. Soil block area was $0.3 \mathrm{~m} \times$ $0.15 \mathrm{~m}$, and depth was $0.3 \mathrm{~m}$. The plant was at the center of the surface. After the soil was carefully washed out, the root was divided into two layers: surface $-15 \mathrm{~cm}$ and $15 \mathrm{~cm}-30 \mathrm{~cm}$ depth. Root length was determined by root scanner (DIAS Root length, Delta-T Devices Ltd, Cambridge, UK).

At midday (10:00 to 12:00), leaf water potential was measured for rice plants grown under upland conditions. These measurements were performed twice a week from 24 July to 26 August in 2007, according to the procedure of Kobata and Takami [21]. Full turgid osmotic potential in leaf was measured on 23 August 2006 for the Takanari, APO, B6144 and Mak hin sung cultivars grown under flooded and upland conditions. The osmotic potential was measured by Psyclometer (Psypro, Wescor Inc., Utah, USA), according to the procedure of Turner et al. [22]. One plant from each replicate was measured to determine leaf water potential and osmotic potential.

The difference between canopy and air temperature was measured by infrared radiation thermometer (thermo tracer TH5104, NEC Sanei, Tokyo, Japan) on 10 August and 15 August in 2007. This measurement was con-

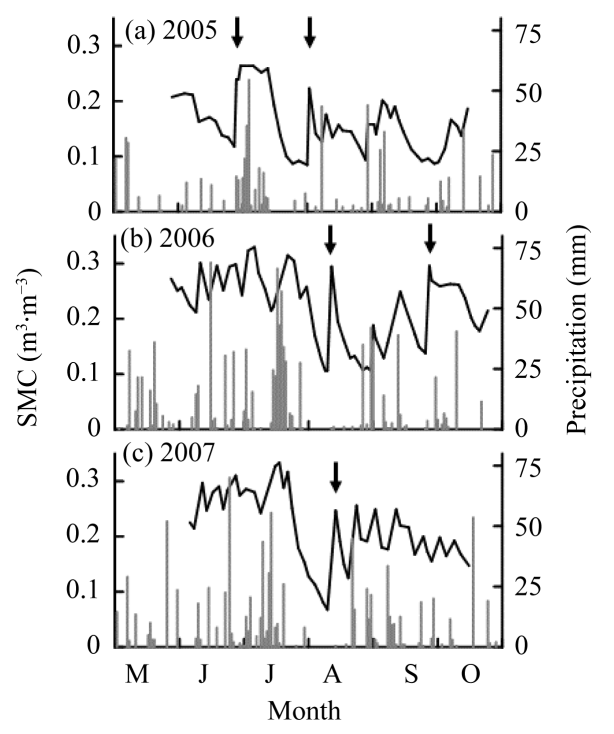

Figure 1. Soil moisture content (SMC) in the upland condition (black) and precipitations (gray) during rice-growing seasons. Arrows denote irrigations. 
ducted when we measured leaf water potential. The depression angle was 20 degrees, and the entire area of a replicate could be viewed in the monitor attached to the thermometer.

The extinction coefficient was measured in 2007. Diffuse non-interceptance radiation was measured with a plant canopy analyzer (LAI-2000. Li-cor, Lincoln, USA) once a week, from 3 weeks after transplanting until heading. The extinction coefficient was calculated with the equation by Dingkuhn et al. [17].

Soil samples were taken from the plow layer $(0 \mathrm{~cm}-20 \mathrm{~cm})$ on 17 October 2007 (after the third season of rice harvest), to determine soil chemical properties. The samples were air-dried and passed through a $2 \mathrm{~mm}$ sieve to remove the debris and stones. We measured soil organic matter (SOM) content, mineralizable $\mathrm{N}$, extractable phosphorus, exchangeable cations and cation exchangeable capacity (CEC). SOM content was determined with the Walkeley method [23]. Mineralizable $\mathrm{N}$ was determined as the increase in the amount of $\mathrm{NH}_{3}-\mathrm{N}$ in soil water after a 4-week anaerobic incubation at $30^{\circ} \mathrm{C}$. CEC and exchangeable cation content were measured by the ammonium acetate extract method at $\mathrm{pH} 7.0$ [24]. Extractable phosphorus content was measured with the Bray P2 Method [25].

\subsection{Analysis of Productivity of Above-Ground Dry Matter}

This study calculated radiation use efficiency (RUE) to analyze the productivity of above-ground total dry matter (TDM). RUE is defined as:

$$
R U E=T D M / I R D
$$

where IRD is intercepted radiation. In this study, RUE was calculated for the entire growth period. TDM was the value at maturity, and IRD was the cumulative value from transplanting to maturity. IRD was calculated from daily solar radiation (Sn), extinction coefficient (k), leaf area index (LAI) and days to maturity from transplanting (DTM) by:

$$
I R D=\sum_{i=1}^{D T M} S n_{i}\left(1-\mathrm{e}^{-k \cdot L A I_{i}}\right)
$$

The daily value of LAI was linearly interpolated from the measurement. Based on the value of Equation (1) and (2), we simplified the components of TDM as:

$$
T D M=D T M \times R U E \times(I R D / D T M)=D T M \times R U E \times I R P D
$$

where IRPD is intercepted radiation per day.

\subsection{Weather Data and Statistical Analysis}

Air temperature and solar radiation were measured in the experimental field. Amount of precipitation was determined from the data obtained at Kyoto Local Meteorological Observatory. Volumetric soil moisture content (SMC) was measured twice a week with the time domain reflectometry (TDR) method (1502B, Tektronix Japan Ltd, Tokyo), according to Topp et al. [26]. For each cultivar, TDR probes $30 \mathrm{~cm}$ and $50 \mathrm{~cm}$ in length were vertically inserted into the soil at each replicate.

Statistical significance of the experimental data was tested with the statistical software SAS version 9.3 (SAS Institute Inc, Cary).

\section{Results}

\subsection{Weather Condition and Soil Moisture Content (SMC)}

Several weeks after transplanting, we experienced a short rainy season, from early June to late July (Figure 1). SMC from surface to $30 \mathrm{~cm}$ depth $\left(\mathrm{SMC}_{0-30}\right)$ remained relatively constant at about $0.25 \mathrm{~m}^{3} \cdot \mathrm{m}^{-3}$ for the period. However, since precipitation during the rainy season in 2005 was extremely limited, irrigation was applied at 27 June. Since precipitation was infrequent and limited after the rainy season (during August and September), $\mathrm{SMC}_{0-30}$ sometimes decreased below $0.1 \mathrm{~m}^{3} \cdot \mathrm{m}^{-3}$. Radiation and air temperature are highest in August, which sometimes induces water stress in rice plants. The Nipponbare, Yumenohatamochi and Mak hin sung cultivars are the first to develop signs of water stress; that is, their leaves start to roll earlier than those of the other cultivars. Irrigation was applied before such leaves exhibited severe rolling. $\mathrm{SMC}_{0-30}$ was not significantly different 
among cultivars (data not shown). Although SMC from $30 \mathrm{~cm}$ to $50 \mathrm{~cm}$ depth $\left(\mathrm{SMC}_{30-50}\right)$ changed with fluctuations in $\mathrm{SMC}_{0-30}$, the change in $\mathrm{SMC}_{30-0}$ was smaller than that in $\mathrm{SMC}_{0-30}$. $\mathrm{SMC}_{30-50}$ rarely fell below 0.25 $\mathrm{m}^{3} \cdot \mathrm{m}^{-3}$.

\subsection{Chemical Properties of the Soil}

Table 1 shows the soil chemical properties of the experimental fields under flooded and upland conditions. Some of the chemical properties and soil textures described by Katsura et al. [16] are also shown in Table 1 as reference. The reference values were obtained during the period when the experimental fields were used continuously as flooded paddy fields during the summer. Soil organic matter content in 2007 was extremely reduced in comparison to 2002 levels. One reason for this difference is sampling time: the soil sample in 2002 was collected after the incorporation of barley plants used for green manure. Mineralizable $\mathrm{N}\left(\mathrm{NH}_{3}-\mathrm{N}\right)$ and CEC were similar between 2002 and 2007. Although soil chemical properties were richer under upland conditions as compared to lowland conditions, the difference was slight.

\subsection{Yield and Dry Matter Production}

Paddy yield (in dry weight) varied with cultivar and with cultivation conditions (upland or flooded) (Figure 2(a)). B6144, APO, Takanari and IR72 recorded higher yields under both upland and flooded conditions, while Nipponbare and Mak hin sung recorded lower yields. The ratio of paddy yield under upland conditions as compared to flooded conditions was almost 1 for IR72 and Mak hin sung. The ratio for Nipponbare was the lowest, 0.53. Among the higher-yield cultivars, Takanari recorded the highest yield under flooded conditions, but it seemed not to adapt to upland conditions. B6144 and IR72 exhibited higher adaptability to both flooded and upland field conditions.

Above-ground total dry matter (TDM) at maturity under flooded and upland field conditions is shown in Figure 2(b). In the flooded condition, the dry weights of B6144 and APO were much higher than those of IR72 and Takanari, while the difference was not evident in the upland condition. The dry weight of Nipponbare under upland conditions was only $60 \%$ of the cultivar's dry weight under flooded conditions.

Table 1. Soil chemical properties and texture quality for the experimental fields under flooded and upland conditions. The 2002 data were measured at the same fields during the period when both fields were managed as flooded fields [16].

\begin{tabular}{|c|c|c|c|}
\hline & \multirow{2}{*}{2002} & \multicolumn{2}{|c|}{2007} \\
\hline & & Flooded & Upland \\
\hline $\mathrm{pH}\left(\mathrm{H}_{2} \mathrm{O}\right)$ & & 5.67 & 5.79 \\
\hline $\mathrm{EC}\left(\mathrm{mS} \cdot \mathrm{m}^{-1}\right)$ & & 7.40 & 4.47 \\
\hline $\mathrm{SOM}\left(\mathrm{g} \cdot \mathrm{kg}^{-1}\right)$ & 70.0 & 39.9 & 48.0 \\
\hline $\mathrm{NH}_{3}-\mathrm{N}\left(\mathrm{mg} \cdot \mathrm{kg}^{-1}\right)$ & 7.65 & 8.65 & 10.95 \\
\hline $\mathrm{P}_{2} \mathrm{O}_{5}\left(\mathrm{mg} \cdot \mathrm{kg}^{-1}\right)$ & & 69.3 & 75.1 \\
\hline $\mathrm{CEC}\left(\mathrm{cmol} \cdot \mathrm{kg}^{-1}\right)$ & 14.2 & 15.2 & 20.5 \\
\hline \multicolumn{4}{|c|}{ Exchangeable cation $\left(\mathrm{cmol} \cdot \mathrm{kg}^{-1}\right)$} \\
\hline K & & 0.28 & 0.28 \\
\hline $\mathrm{Ca}$ & & 3.40 & 4.26 \\
\hline $\mathrm{Mg}$ & & 0.41 & 0.53 \\
\hline \multicolumn{4}{|c|}{ Texture $\left(\mathrm{kg} \cdot \mathrm{kg}^{-1}\right)$} \\
\hline Sand & 0.64 & & \\
\hline Silt & 0.27 & & \\
\hline Clay & 0.09 & & \\
\hline
\end{tabular}



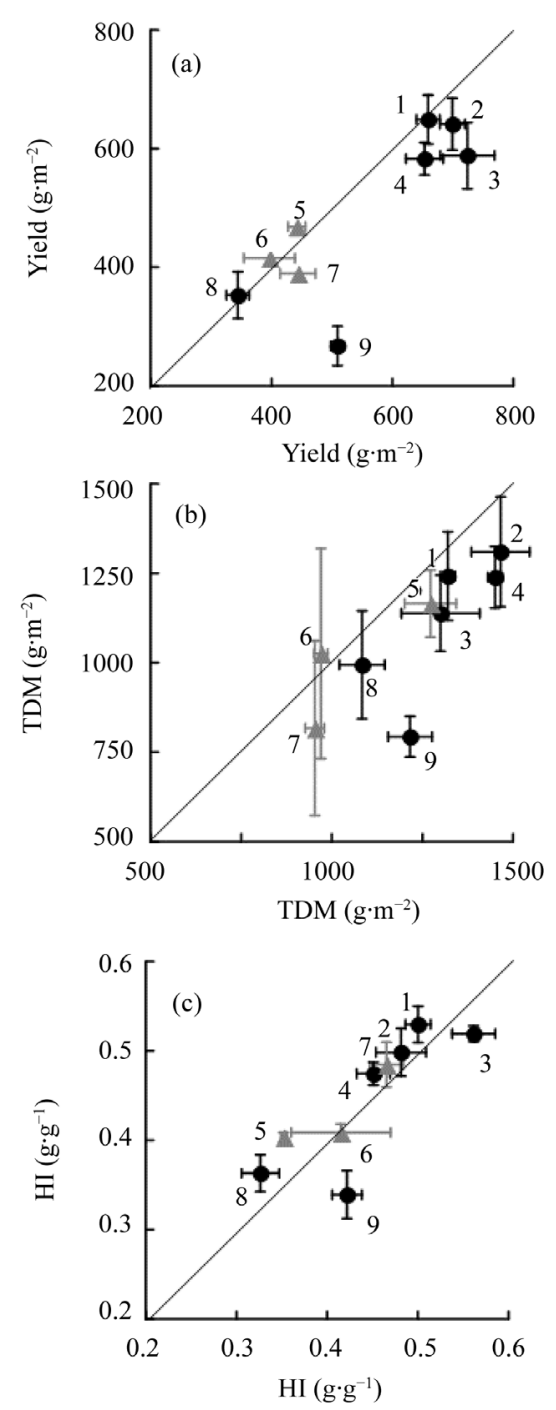

Figure 2. Comparison of paddy yield (a), total dry matter (TDM, b) and harvest index (HI, c) between the flooded condition (x-axis) and the upland condition (y-axis). Values are average and s.e. for 3 years (black circles) or 2 years (gray triangles). Numbers denote cultivar; 1: IR72, 2: B6144, 3: Takanari, 4: APO, 5: Banten, 6: WAB, 7: Yumenohatamochi, 8: Mak hing sung, 9: Nipponbare.

Harvest indexes $(\mathrm{HI}=$ yield/TDM) for IR72, B6144 and APO under upland conditions were slightly higher than under flooded conditions (Figure 2(c)). The HI of Takanari under upland conditions was slightly lower than under flooded. The ratio (upland/flooded) was 0.92. The HI for Nipponbare under the upland condition was reduced $20 \%$ in the flooded condition.

Correlation coefficients comparing values in upland conditions to those in flooded conditions indicate that the decrease in yield under upland conditions derived mostly from decreases in TDM $\left(r=0.85^{* *}, \mathrm{n}=24\right)$, as opposed to $\mathrm{HI}(\mathrm{r}=0.30)$.

\subsection{Analysis of Above-Ground Total Dry Matter Productivity}

Components of dry matter productivity as expressed in Equation (3) are shown in Figure 3. On average, the time to maturity from transplanting under upland conditions was 2 weeks longer than under flooded conditions (Figure 3(a)). IRPD and RUE under upland conditions were about 10\% lower than under flooded conditions 

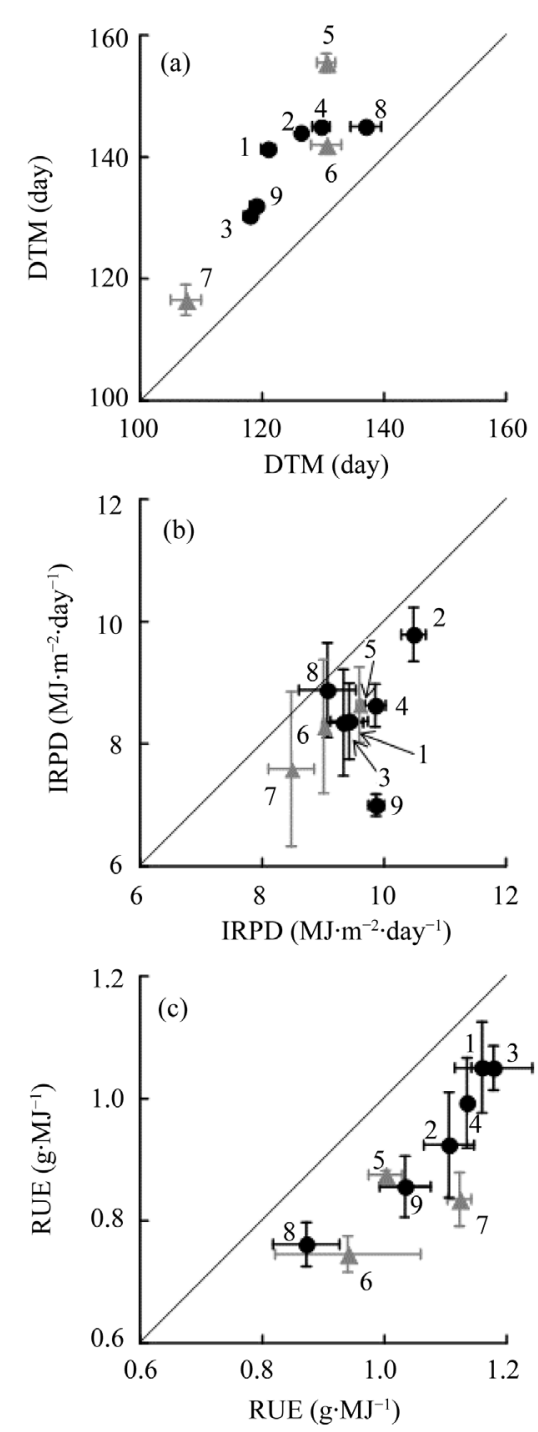

Figure 3. Comparison of days to maturity from transplanting (DTM, a), intercepted radiation per day (IRPD, b), and radiation use efficiency (RUE, c), between the flooded condition (x-axis) and the upland condition (y-axis). Symbols are the same as in Figure 2.

(Figure 3(a) and Figure 3(b)). B6144 displayed significantly higher IRPD than the other cultivars, under both irrigated and flooded conditions. In comparison to other cultivars, Takanari and IR72 showed relatively higher RUE, under both flooded and upland conditions.

Correlation coefficients for the ratios of values under upland as compared to flooded conditions indicate that the decrease in TDM under upland conditions was mostly derived from the decrease in RUE $\left(r=0.66^{* *}, \mathrm{n}=24\right)$, as opposed to IRPD $(r=0.14)$ or days to maturity (DTM) $(r=0.04)$.

\subsection{Factors Associated with Intercepted Radiation Per Day (IRPD)}

As shown in Equations (2) and (3), IRPD is a function of LAI and DTM. IRPD was significantly correlated with LAI at heading (Figure 4). Although the difference was not significant, the regression line for IRPD vs. LAI differed between flooded and upland conditions. Lower IRPD as compared to LAI in the upland condition was derived from a slower LAI expansion rate and longer time to maturity (due to reduced solar radiation later in the growing season). 


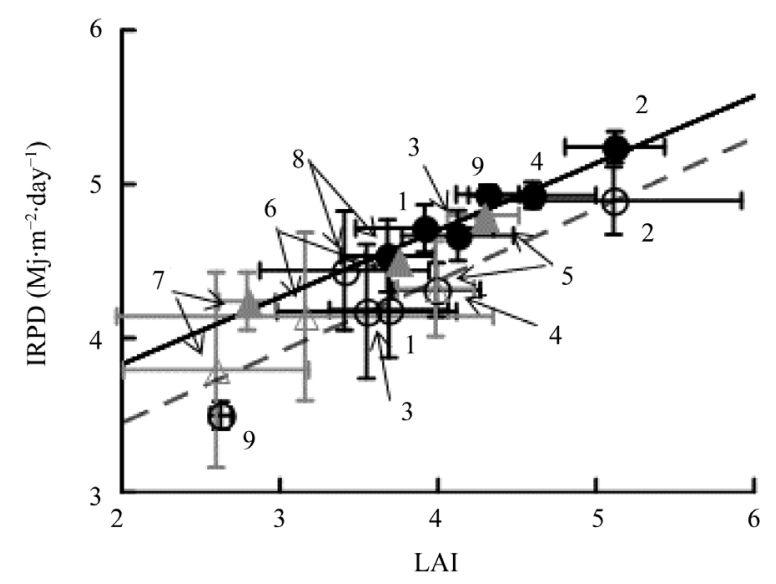

Figure 4. Relationship between LAI at heading and intercepted radiation per day under flooded (closed) and upland (open) conditions. We obtained regression lines for flooded (solid) and upland (dashed) conditions. Symbols are the same as in Figure 2.

For B6144, IR72 and Mak hing sung, LAI at heading was the same in flooded and upland conditions (Figure 5). The LAI ratio (upland/flooded) was about 0.85 for Takanari and Apo, and 0.6 for Nipponbare. The ratio was positively associated with root length density (RLD) under the upland condition. We did not observe a significant difference in root distribution (i.e., the ratio of RLD between $0 \mathrm{~cm}-15 \mathrm{~cm}$ depth and $15 \mathrm{~cm}-30 \mathrm{~cm}$ depth) among cultivars (data not shown).

\subsection{Factors Associated with Radiation Use Efficiency (RUE)}

Differences among cultivars in leaf water potential (LWP) were larger under lower soil moisture content (SMC), as compared to higher SMC (Figure 6). In severely water-deficient conditions (under less than $0.1 \mathrm{~m}^{3} \cdot \mathrm{m}^{-3}$ SMC), Apo, Takanari and IR72 exhibited higher LWP, and Nipponbare displayed the lowest LWP. Although full turgid osmotic potential was lower under upland conditions (-1.02 MPa) than under flooded conditions $(-0.86 \mathrm{MPa})$, we did not observe a significant difference among cultivars.

The temperature difference between canopy and air (TD; canopy - air) was associated with LWP under the upland condition (Figure 7). Canopies for which LWP was higher exhibited lower canopy temperatures, indicating that the transpiration rate was higher. As a result, higher RUE under the upland condition was associated with higher LWP in severely water deficient conditions (Figure 8).

\section{Discussion}

In this study, cultivar differences in adaptability to moderately water-stressed upland conditions, in terms of yield, were associated with the productivity of above-ground total dry matter (TDM) rather than harvest index (HI). Peng et al. [15] reported a similar contribution of TDM to yield loss under aerobic conditions. As shown in Figure 2, although maintenance of HI under upland conditions remains an important issue for certain lowland cultivars (such as Takanari and Nipponbare), the major issue is maintenance of TDM productivity. Furthermore, Bouman et al. [3] reported that the response to water availability differed between aerobic and lowland rice cultivars. Aerobic rice cultivars exhibited more stable harvest indexes, and reductions in yield were caused by a decline in TDM. In lowland rice cultivars, reductions in yield were primarily caused by decreases in HI.

The analysis in this study indicated that decreases in TDM under upland conditions were closely correlated with decreases in radiation use efficiency (RUE). Under flooded and upland conditions, IR72 demonstrated better performance in terms of TDM; this difference was resulted from higher RUE. Meanwhile, the highest productivity in TDM, observed in B6144, was associated with the highest IRPD, which derived from the largest LAI. Takanari showed higher RUE under both flooded and upland conditions, but it did not produce more TDM. This suggests that the ability to expand LAI is necessary to improve TDM productivity and, therefore, to increase yield under both flooded and upland conditions. 


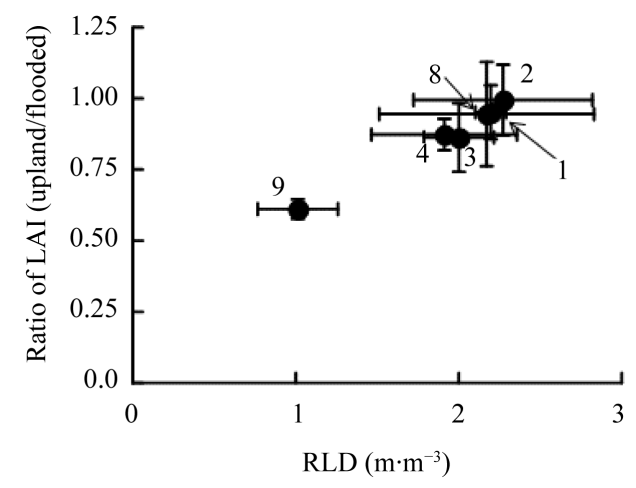

Figure 5. Relationship between root length density (RLD) and ratio of LAI under upland conditions as opposed to flooded conditions. Symbols are the same as in Figure 2.

\section{$\operatorname{SMC}\left(\mathrm{m}^{3} \cdot \mathrm{m}^{-3}\right)$}

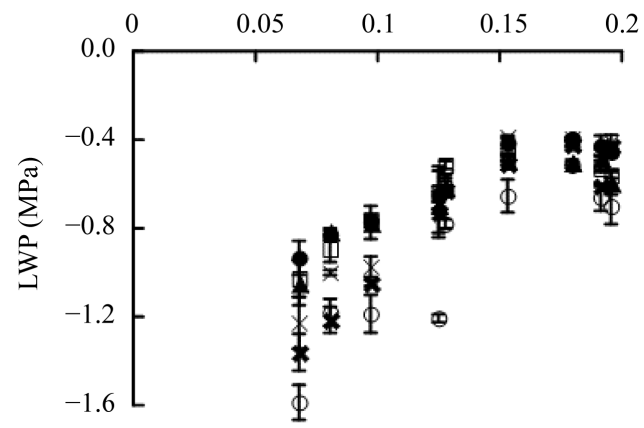

Figure 6. Relationship between soil moisture content (SMC) and leaf water potential (LWP) at daytime under the upland condition. Error bars shows s.e. for 3 replicates. $\boldsymbol{\Delta}$ : IR72, $\times$ : B6144, $\square$ : Takanari, $\bigcirc$ : APO, $\mathbf{x}$ : Mak hing sung, $\bigcirc$ : Nipponbare.

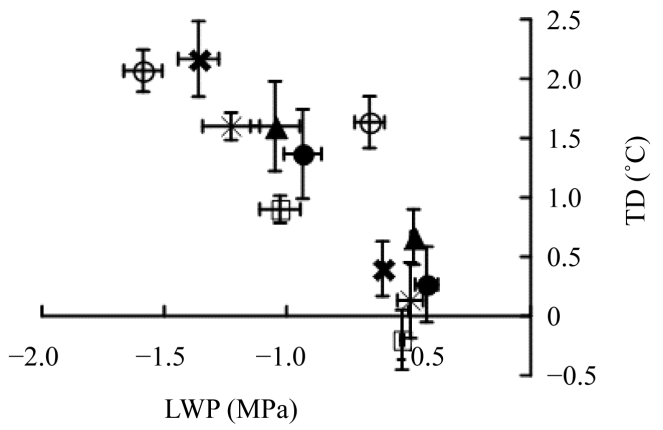

Figure 7. Temperature difference between canopy and air (TD; canopy - air) as a function of leaf water potential (LWP), at daytime under the upland condition. Symbols are the same as in Figure 6.

Comparison with Nipponbare (Figure 5) suggested that a decrease in the ratio of LAI under upland conditions vs. LAI potential as determined under flooded conditions was associated with root length density (RLD). Wade et al. [27] reported that genotypes with superior drought recovery have larger leaf biomass and greater root length increases during drought. Tanguiling et al. [28] indicated that leaf elongation rate is a function of 


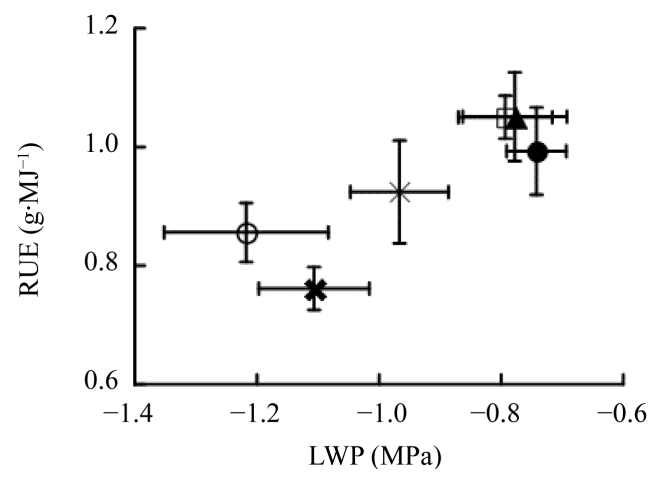

Figure 8. Relationship between radiation use efficiency (RUE) and leaf water potential (LWP). LWP values are the average of 3 measurements, which were conducted under $<0.1 \mathrm{~m}^{3} \cdot \mathrm{m}^{-3}$ soil moisture content in the upland condition (see Figure 6). Error bars shows s.e. Symbols are the same as in Figure 6.

dawn leaf water potential (LWP). Notably, LWP tends to be maintained in genotypes with large RLD [29] [30]. Thus, root characteristics are important for leaf expansion under conditions of water stress. However, conflicting evidence has also been reported (e.g., [10]). Kamoshita et al. [10] reported the lack of any clear relationship between LWP and RLD. In this study, we measured pre-dawn LWP in the severely water-deficient condition (under $<0.1 \mathrm{~m}^{3} \cdot \mathrm{m}^{-3} \mathrm{SMC}$ ). The differences among cultivars were so small that significant relationships between pre-dawn LWP and RLD, and between pre-dawn LWP and the LAI ratio, were not observed (data not shown). Although there was a slight association between root depth $(>30 \mathrm{~cm}$ depth) and leaf elongation rate, the contribution of root growth to water stress adaptability may be small and dependent on environmental variables [31].

On the other hand, RUE in the upland condition was associated with LWP in this study. Hirasawa et al. [32] reported that leaf photosynthesis rate is a function of LWP. Therefore, the ability to maintain LWP under water deficit is important for adaptability to upland conditions. As mentioned above, it is not clear that larger RLD maintains higher LWP. A difference in resistance to water transport could explain the results obtained in this study [33]. Although root system resistance is the primary determinant of plant resistance [33] [34], xylem cavitation markedly increases resistance under drought conditions [35]. Such cavitation is also reported in rice [36]. Therefore above-ground characteristics may be more important than underground qualities in attempts to improve productivity under water-stressed conditions [31].

This study employed the temperature difference between air and canopy (TD), measured by infrared radiation thermometer, to evaluate transpiration and photosynthesis in the canopy. The method indirectly evaluated cultivar differences in the ability to maintain LWP against soil moisture deficit, as shown in Figure 7. TD was first used by Idso et al. [37] to evaluate water stress in crops; many subsequent studies have proved the technique's effectiveness (e.g., [38]). However, it is well known that TD as an indicator of water stress is highly dependent on the circumstances of evaluation, such as solar radiation vapor pressure deficit [39]. Although this study seemed to effectively evaluate plant status, accuracy may depend on the timing of measurements (in our study, midday [10:00 to 12:00] on a day with clear skies, for a week). In order to evaluate more cultivars and lines or longer durations, it will be necessary to use a water stress index [39] or to standardize according to Horie et al. [40].

Peng et al. [15] reported that grain yield of Apo decreased as cultivation continued under aerobic conditions in the Philippines. We did not observe a similar decrease in this study. For example, Apo yield was $557 \mathrm{~g} \cdot \mathrm{m}^{-2}$ in 2005 and $638 \mathrm{~g} \cdot \mathrm{m}^{-2}$ in 2007 under upland conditions. The variation between these two observations may be derived from that between tropic and temperate climates, or from the difference between double cropping of rice vs. green manure cropping during the off-season. However, since continuous cropping was reported to injure upland rice in Japan, aerobic rice may not be suitable to continuous cropping. Nishio and Kusano [41] [42] indicated that fungi are one of the major causes of plant injury in Japan.

This study revealed that larger LAI growth rate and higher RUE are necessary to achieve higher yields under moderately water stressed upland conditions, where yield comparable with that of lowland conditions can be 
obtained. The results also indicate that improving only one of the two traits is not adequate. Thus, drought avoidance (through the acquisition of soil moisture) is more important under such conditions than drought tolerance (to limit water use). We also showed that RLD and LWP are associated with LAI growth and RUE, respectively. As shown in this study, infrared radiation thermometer is suited to evaluate RUE [40]. In order to evaluate LAI growth, canopy analyzer may be suited [17] [43] [44]. The data obtained with canopy analyzer were not used to calculate LAI in this study because the measurements were conducted only in 2007. Nonetheless, the values obtained by canopy analyzer corresponded closely to those obtained by destructive measurement. This study tested two aerobic cultivars, Apo and B6144 [7]. B6144 displayed better performance in terms of yield and particularly TDM productivity. However, the results also indicated that HI and RUE for B6144 are not as high as for IR72 and Takanari, suggesting that we can still improve productivity.

\section{Conclusion}

The results in this experiment suggest that the adaptability of high-yielding rice cultivars to moderately water stressed upland condition is mostly derived from the productivity of TDM rather than that of paddy yield per unit TDM under upland condition. Higher TDM productivity is caused by higher RUE, which associates with higher LWP. Because an infrared radiation thermometer is a useful tool to quickly assess LWP and then RUE, it might also be useful to select genotypes for breeding.

\section{References}

[1] Horie, T., Shiraiwa, T., Homma K., Katsura, K., Maeda, S. and Yoshida, H. (2005) Can Yield of Lowland Rice Resume the Increases That They Showed in the 1980s? Plant Production Science, 8, 259-274. http://dx.doi.org/10.1626/pps.8.259

[2] Homma, K., Shiraiwa, T. and Horie, T. (2014) Variability of Rice Production in Monsoon Asia. The Open Agriculture Journal, 8, 28-34. http://dx.doi.org/10.2174/1874331501408010028

[3] Bouman, B.A.M. and Tuong, T.P. (2001) Field Water Management to Save Water and Increase its Productivity in Irrigated Lowland Rice. Agricultural Water Management, 49, 11-30. http://dx.doi.org/10.1016/S0378-3774(00)00128-1

[4] Hossain, M. (1998) Sustaining Food Security in Asia: Economic, Social and Political Aspects. In: Dowling, N.G., Greenfield, S.M. and Fischer, K.S., Eds., Sustainability of Rice in the Global Food System, Pacific Basin Study Center, Davis, CA and IRRI, Manila, 19-43.

[5] Kato, Y. and Katsura, K. (2014) Rice Adaptation to Aerobic Soils: Physiological Considerations and Implications for Agronomy. Plant Production Science, 17, 1-12. http://dx.doi.org/10.1626/pps.17.1

[6] Yun, S.I., Wada, Y., Maeda, T., Miura, K. and Watanabe, K. (1997) Growth and Yield of Japonica $\times$ Indica Hybrid Cultivars under Direct Seeding and Upland Cultivation Conditions. Japanese Journal of Crop Science, 66, 386-393. http://dx.doi.org/10.1626/jcs.66.386

[7] Atlin, G.N., Lafitte, H.R., Tao, D., Laza, M., Amante, M. and Courtois, B. (2006) Developing Rice Cultivars for High-Fertility Upland Systems in the Asian Tropics. Field Crops Research, 97, 43-52. http://dx.doi.org/10.1016/j.fcr.2005.08.014

[8] Yoshida, S. and Hasegawa, S. (1982) The Rice Root System, its Development and Function. In: Drought Resistance in Crops with the Emphasis on Rice, IRRI, Manila, 83-96.

[9] Fukai, S. and Cooper, M. (1995) Development of Drought-Resistant Cultivars Using Physio-Morphological Traits in Rice. Field Crops Research, 40, 67-86. http://dx.doi.org/10.1016/0378-4290(94)00096-U

[10] Kamoshita, A., Wade, L.J. and Yamaushi, A. (2000) Genotypic Variation in Response of Rainfed Lowland Rice to Drought and Rewatering. Plant Production Science, 3, 189-196. http://dx.doi.org/10.1626/pps.3.189

[11] Kato, Y., Tajima, R., Homma, K., Toriumi, A., Yamagishi, J., Shiraiwa, T. Mekwatanakarn, P. and Jongdee, B. (2013) Root Growth Response of Rainfed Lowland Rice to Aerobic Conditions in Northeastern Thailand. Plant and Soil, 368, 557-567. http://dx.doi.org/10.1007/s11104-012-1538-3

[12] Lafitte, H.R., Price, A.H. and Courtois, B. (2004) Yield Response to Water Deficit in an Upland Rice Mapping Population: Associations among Traits and Genetic Markers. Theoretical Applied Genetics, 109, 1237-1246. http://dx.doi.org/10.1007/s00122-004-1731-8

[13] Kato, Y., Kamoshita, A., Yamagishi, J., Imoto, H. and Abe, J. (2007) Growth of Rice (Oryza sativa L.) Cultivars under Upland Conditions with Different Levels of Water Supply. 3. Root System Development, Soil Moisture Change and Plant Water Status. Plant Production Science, 10, 3-13. http://dx.doi.org/10.1626/pps.10.3 
[14] Peng, S., Laza, R.C., Visperas, R.M., Sanico, A.L., Cassman, K.G. and Khush, G.S. (2000) Grain Yield of Rice Cultivars and Lines Developed in the Philippines since 1966. Crop Science, 40, 307-314. http://dx.doi.org/10.2135/cropsci2000.402307x

[15] Peng, S., Bouman, B., Visperas, R.M., Castañeda, A., Nie, L. and Park, H.K. (2006) Comparison between Aerobic and Flooded Rice in the Tropics; Agronomic Performance in an Eight-Season Experiment. Field Crops Research, 96, 252259. http://dx.doi.org/10.1016/j.fcr.2005.07.007

[16] Katsura, K., Maeda, S., Lubis, I., Horie, T., Cao, W. and Shiraiwa, T. (2008) The High Yield of Irrigated Rice in Yunnan, China: “A Cross Location Analysis”. Field Crops Research, 107, 1-11. http://dx.doi.org/10.1016/j.fcr.2007.12.007

[17] Dingkuhn, M., Jhonson, D.E., Sow, A. and Audebert, A.Y. (1999) Relationship between Upland Rice Canopy Characteristics and Weed Competitiveness. Field Crops Research, 61, 79-95. http://dx.doi.org/10.1016/S0378-4290(98)00152-X

[18] Hayata, M., Ohishi, H., Chien, Y., Matsumoto, H., Wada, T., Isobe, K. and Ishii, R. (2005) Agronomic Studies on the Characteristics of Dry Matter Production and Grain Yielding of NERICA. 1. Characteristics under the Irrigated Upland Conditions. Japanese Journal of Crop Science, 74, 246-247. (In Japanese)

[19] Ikehashi, H. and Araki, H. (1984) Varietal Screening of Compatibility Types Revealed in $F_{1}$ Fertility of Distant Crosses in Rice. Japanese Journal of Breeding, 34, 304-313. http://dx.doi.org/10.1270/jsbbs1951.34.304

[20] Asai, H., Saito, K., Samson, B., Songyikhangsuthor, S., Homma, K., Shiraiwa, T., Kiyono, Y., Inoue, Y. and Horie, T. (2009) Yield Response of Indica and Tropical Japonica Genotypes to Soil Fertility Conditions under Rainfed Uplands in Northern Laos. Field Crops Research, 112, 141-148. http://dx.doi.org/10.1016/j.fcr.2009.02.010

[21] Kobata, T. and Takami, S. (1984) Estimation of the Leaf Water Potential in Rice by the Pressure Chamber Technique. Japanese Journal of Crop Science, 53, 290-298. (In Japanese with English summary) http://dx.doi.org/10.1626/jcs.53.290

[22] Turner, N.C., O’Toole, J.C., Cruz, R.T., Namuco, O.S. and Ahmad, S. (1986) Responses of Seven Diverse Rice Cultivars to Water Deficits I. Stress Development, Canopy Temperature, Leaf Rolling and Growth. Field Crops Research, 13, 257-271. http://dx.doi.org/10.1016/0378-4290(86)90027-4

[23] Walkley, A. (1947) A Critical Examination of a Rapid Method for Determining Organic Carbon in Soils-Effect of Variations in Digestion Conditions and of Inorganic Soil Constituents. Soil Science, 63, 251-264. http://dx.doi.org/10.1097/00010694-194704000-00001

[24] Soil and Plant Analysis Council (1999) Soil Analysis Handbook of Reference Methods. CRC Press, Boca Raton, 1-247.

[25] Bray, R.H. and Kurtz, L.T. (1945) Determination of Total, Organic, and Available Forms of Phosphorus in Soils. Soil Science, 59, 39-46. http://dx.doi.org/10.1097/00010694-194501000-00006

[26] Topp, G.C., Davis, J.L. and Annan, A.P. (1980) Electromagnetic Determination of Soil Water Content: Measurements in Coaxial Transmission Lines. Water Resource Research, 16, 574-582. http://dx.doi.org/10.1029/WR016i003p00574

[27] Wade, L.J., Kamoshita, A., Yamauchi, A. and Azhiri-Sigari, T. (2000) Genotypic Variation in Response of Rainfed Lowland Rice to Drought and Rewatering. I. Growth and Water Use. Plant Production Science, 3, 173-179. http://dx.doi.org/10.1626/pps.3.173

[28] Tanguilig, V.C., Yambao, E.B., O’toole, J.C. and De Datta, S.K. (1987) Water Stress Effects on Leaf Elongation, Leaf Water Potential, Transpiration, and Nutrient Uptake of Rice, Maize, and Soybean. Plant and Soil, 103, 155-168. http://dx.doi.org/10.1007/BF02370385

[29] Mambani, B. and Lal, R. (1983) Response of Upland Rice Varieties to Drought Stress. 1. Relation between Root System Development and Leaf Water Potential. Plant and Soil, 73, 59-72. http://dx.doi.org/10.1007/BF02197757

[30] Ekanayake, I.J., O’Toole, J.C., Garrity, D.P. and Masajo, T.M. (1985) Inheritance of Root Characters and Their Relations to Drought Resistance in Rice. Crop Science, 25, 927-933. http://dx.doi.org/10.2135/cropsci1985.0011183X002500060007x

[31] Price, A.H., Cairns, J.E., Horton, P., Jones, H.G. and Griffiths, H. (2002) Linking Drought-Resistance Mechanisms to Drought Avoidance in Upland Rice Using a QTL Approach: Progress and New Opportunities to Integrate Stomatal and Mesophyll Responses. Journal of Experimental Botany, 53, 989-1004. http://dx.doi.org/10.1093/jexbot/53.371.989

[32] Hirasawa, T., Iida, Y. and Ishihara, K. (1989) Dominant Factors in Reduction of Photosynthetic Rate Affected by Air Humidity and Leaf Water Potential in Rice Plants. Japanese Journal of Crop Science, 58, 383-389. http://dx.doi.org/10.1626/jcs.58.383

[33] Boyer, J.S. (1985) Water Transport. Annual Review of Plant Physiology, 36, 473-516. http://dx.doi.org/10.1146/annurev.pp.36.060185.002353

[34] Hirasawa, T., Tsuchida, M. and Ishihara, K. (1992) Relationship between Resistance to Water Transport and Exudation Rate and the Effect of the Resistance on the Midday Depression of Stomatal Aperture in Rice Plants. Japanese Journal of Crop Science, 61, 145-152. http://dx.doi.org/10.1626/jcs.61.145 
[35] Milburn, J.A. (1993) Cavitation. A Review: Past, Present and Future. In: Borghetti, M., Grace, J. and Raschi, A., Eds., Water Transport in Plants under Climatic Stress, Cambridge University Press, Cambridge, 14-26.

[36] Stiller, V., Lafitte, H.R. and Sperry, J.S. (2003) Hydraulic Properties of Rice and the Response of Gas Exchange to Water Stress. Plant Physiology, 132, 1698-1706. http://dx.doi.org/10.1104/pp.102.019851

[37] Idso, S.B., Jackson, R.D. and Reginato, R.J. (1977) Remote Sensing of Crop Yield. Science, 196, 19-25. http://dx.doi.org/10.1126/science.196.4285.19

[38] Fukuoka, M., Iwama, K. and Jitsuyama, Y. (2006) Difference between Canopy Temperature and Air Temperature as a Criterion for Drought Avoidance in Upland Rice Varieties under Field Conditions in Japan. Japanese Journal of Crop Science, 75, 57-67. (In Japanese with English abstract) http://dx.doi.org/10.1626/jcs.75.57

[39] Jackson, R.D., Idso, S.B., Reginato, R.J. and Pinter Jr., P.J. (1981) Canopy Temperature as a Crop Water Stress Indicator. Water Resource Research, 17, 1133-1138. http://dx.doi.org/10.1029/WR017i004p01133

[40] Horie, T., Matsuura, S., Takai, T., Kuwasaki, K., Ohsumi, A. and Shiraiwa, T. (2006) Genotypic Difference in Canopy Diffusive Conductance Measured by a New Remote-Sensing Method and Its Association with the Difference in Yield Potential in Rice. Plant, Cell and Environment, 29, 653-660. http://dx.doi.org/10.1111/j.1365-3040.2005.01445.x

[41] Nishio, M. and Kusano, S. (1975) Effect of Fungi Associated with Roots on the Growth of Continuously Cropped Upland Rice. Soil Science and Plant Nutrition, 21, 161-171. http://dx.doi.org/10.1080/00380768.1975.10432632

[42] Nishio, M. and Kusano, S. (1975) Effect of Root Residues on the Growth of Upland Rice. Soil Science and Plant Nutrition, 21, 391-395. http://dx.doi.org/10.1080/00380768.1975.10432654

[43] Stroppiana, D., Boschetti, M., Confalonieri, R., Bocchi, S. and Brivio, P.A. (2006) Evaluation of LAI-2000 for Leaf Area Index Monitoring in Paddy Rice. Field Crops Research, 99, 167-170. http://dx.doi.org/10.1016/j.fcr.2006.04.002

[44] Hirooka, Y., Irie, T., Homma, K., Shiraiwa, T. and Toriumi, A. (2013) Analysis of Genotypic Variation of Leaf Canopy Dynamics in Rice by Using Plant Canopy Analyzer. Journal of Crop Research, 58, 51-56. 